\title{
Remdesivir como tratamiento para COVID-19
}

\author{
Remdesivir for the treatment of COVID-19
}

\section{Comentado de:}

Beigel JH, et al. N Engl J Med. 2020 Oct 8;NEJMoa2007764. doi: 10.1056/NEJMoa2007764. PMID: $32445440^{1}$

\section{Objetivo}

Evaluar la eficacia clínica y la seguridad del remdesivir endovenoso en pacientes adultos hospitalizados con COVID-19.

\section{Diseño}

Ensayo clínico multicéntrico, controlado, aleatorizado, doble ciego, comparado con placebo.

\section{Lugar}

Estados Unidos, Dinamarca, Reino Unido, Grecia, Alemania, Corea, México, España, Japón y Singapur.

\section{Pacientes}

Fueron incluidas en el estudio personas mayores de 18 años, hospitalizadas por síntomas compatibles con COVID-19, con evidencia de compromiso de la vía aérea inferior (VAI) y un resultado de la reacción en cadena de la polimerasa con transcriptasa inversa (RT-PCR, por sus iniciales en inglés) positivo para SARSCoV-2, obtenido en las 72 horas previas al enrolamiento.

Se consideraron como pruebas de compromiso de la VAI la presencia de infiltrados en una imagen radiográfica; la saturación periférica de oxígeno al aire ambiente menor o igual a $94 \%$; o el requerimiento de oxígeno suplementario, ventilación mecánica o membrana de oxigenación extracorpórea.

Durante el estudio, el criterio de RT-PCR fue modificado por las limitaciones en la capacidad de realizar una nueva prueba, permitiendo incorporar a aquellos pacientes que, a pesar de tener RT-PCR positiva para SARS-CoV-2 más antigua, persistieran con evidencia clínica de la enfermedad.

\section{Intervención}

Los pacientes fueron asignados al azar a través de un sistema web de entrada de datos, en una proporción 1:1 a recibir remdesivir (dosis de carga de 200 mg EV en el día 1, seguido de 100 $\mathrm{mg}$ diarios por hasta nueve días adicionales), o placebo, por hasta diez días. La aleatorización fue estratificada según el sitio en el que se realizó el estudio y la severidad de la enfermedad al momento del enrolamiento.

\section{Evaluación de los factores de riesgo}

Fueron consideradas la edad media de los pacientes, el género, la raza o grupo étnico, las comorbilidades, el tiempo transcurrido desde el inicio de los síntomas hasta la aleatorización, y el grado de severidad de la enfermedad al momento del enrolamiento. No se observaron desequilibrios sustanciales en la distribución de las características basales entre los grupos.

\section{Medición de resultados principales}

El desenlace primario fue definido como el tiempo medio de recuperación en el grupo remdesivir en comparación al grupo placebo. Se consideró como estado de recuperación al primer día en que el paciente satisficiera las categorías uno a tres de una escala clínica ordinal de ocho categorías durante los 28 días de seguimiento (ver Tabla 1).

Los desenlaces secundarios fueron la mortalidad a los días 14 y 28 , la categoría clínica ordinal al día 15, y los efectos adversos grado tres, cuatro y severos.
Tabla 1. Escala ordinal de ocho categorías de severidad del cuadro clínico utilizada para definir los desenlaces en este estudio.

\begin{tabular}{|c|l|}
\hline Categoría & Descripción del estado del paciente \\
\hline 1 & No hospitalizado, sin limitaciones en sus actividades \\
\hline 2 & $\begin{array}{l}\text { No hospitalizado, con limitación en sus actividades, } \\
\text { requerimiento de oxígeno en el hogar, o ambos }\end{array}$ \\
\hline 3 & $\begin{array}{l}\text { Hospitalizado, no requiere oxígeno suplementario y ya no } \\
\text { requiere atención médica continua (se usa si la hospitali- } \\
\text { zación se extendió por razones de control de la infección) }\end{array}$ \\
\hline 4 & $\begin{array}{l}\text { Hospitalizado, no requiere oxígeno suplementario pero } \\
\text { necesita atención médica continua (debido al COVID-19 } \\
\text { u otras condiciones médicas) }\end{array}$ \\
\hline 5 & $\begin{array}{l}\text { Hospitalizado, requiere oxígeno suplementario } \\
\text { Hospitalizado, requiere ventilación no invasiva o uso de } \\
\text { dispositivos de oxígeno de alto flujo }\end{array}$ \\
\hline 6 & $\begin{array}{l}\text { Hospitalizado, recibe ventilación mecánica invasiva u oxi- } \\
\text { genación por membrana extracorpórea (ECMO, por sus } \\
\text { iniciales en inglés) }\end{array}$ \\
\hline 8 & \begin{tabular}{l} 
Muerte \\
\hline
\end{tabular} \\
\hline
\end{tabular}

\section{Resultados principales}

Fueron incluidos 1062 pacientes (541 asignados a remdesivir y 521 a placebo). Aquellos asignados al grupo remdesivir tuvieron un tiempo medio de recuperación de diez días (Intervalo de confianza [IC] del 95\%, 9 a 11), en comparación con 15 días (IC $95 \%, 13$ a 18) en quienes recibieron placebo (razón de tasas 1,29; IC $95 \%, 1,12$ a 1,49; P <0,001), con particular beneficio de los hospitalizados en sala general con oxigenoterapia (categoría 5 de la escala ordinal).

En cuanto a la medición de la mortalidad al día 15, el grupo tratado con remdesivir tuvo un $30 \%$ menos de probabilidad de muerte que el grupo tratado con placebo (hazard ratio 0,73 ; IC $95 \%, 0,52$ a 1,03). Las estimaciones de mortalidad de Kaplan Meier al día 15 fueron del $6,7 \%$ con remdesivir y del $11,9 \%$ con placebo.

Se reportaron eventos adversos serios en 131 de 532 pacientes que recibieron remdesivir $(24,6 \%$ ) y en 163 de los 516 pacientes que recibieron placebo $(31,6 \%)$.

\section{Conclusión}

Un curso de diez días de remdesivir se asoció con una disminución en el tiempo de recuperación en adultos hospitalizados con COVID-19 y evidencia de infección del tracto respiratorio inferior (particularmente en los pertenecientes a la categoría 5 de la escala ordinal de severidad del cuadro clínico - pacientes hospitalizados en sala general con oxigenoterapia).

Fuentes de financiamiento/Conflicto de interés de los autores: El estudio fue financiado parcialmente con fondos federales de los EE.UU. y los gobiernos de Dinamarca, Japón, México y Singapur.

El autor principal reportó no tener conflictos de interés. Algunos autores reportaron haber recibido becas de universidades y otras entidades públicas. Varios autores declararon haber recibido becas, honorarios y soporte no financiero de laboratorios y fundaciones con fines de lucro, fuera de los fines del presente estudio. 


\section{Comentario}

Desde que en diciembre de 2019 se logró identificar al SARS-CoV2 como responsable del COVID-19, múltiples agentes terapéuticos fueron evaluados para hacerle frente. El remdesivir es un fármaco antiviral de amplio espectro, que se había identificado tempranamente como una promesa contra el coronavirus, dado que había demostrado inhibir su replicación in vitro. Al poco tiempo de declarada la pandemia, la Administración de Drogas y Alimentos de los EE.UU. (en inglés, FDA) aprobó su uso de emergencia y desde entonces ha sido evaluado en múltiples ensayos clínicos, obteniendo evidencia contradictoria $^{2}$. En el caso de este trabajo, un reporte favorable al remdesivir había conducido a la aprobación de su indicación en todo paciente hospitalizado con COVID moderado. Sin embargo, tras analizar el artículo en detalle, teniendo en cuenta los costos y la existencia de tratamientos alternativos, no estamos tan seguras de que su efecto represente un beneficio global en términos de salud pública.

Consideramos que el principal problema metodológico de este trabajo fue la pronta publicación de sus resultados antes de finalizado el seguimiento total planificado. Sin embargo, se sabe que los ensayos que terminan antes de lo planificado, especialmente por resultados aparentemente beneficiosos, sobreestiman sistemáticamente los efectos del tratamiento. Si bien la cantidad de eventos fue considerable (más de 400 recuperaciones), no existieron reglas pre-establecidas con criterios estrictos para la finalización temprana del ensayo, sino que la decisión de interrumpir el estudio estuvo basada en revisiones internas frecuentes, lo cual podría implicar aún un mayor riesgo de sesgo ${ }^{3,4}$

En cuanto a los resultados, si bien fue informado que los pacientes asignados al grupo remdesivir tuvieron un tiempo medio de recuperación de 10 días (IC 95\%, 9 a 11), en comparación con 15 días (IC 95\%, 13 a 19) en aquellos que recibieron placebo, al evaluar los resultados según la gravedad de la enfermedad, se observa que el beneficio no es homogéneo en todas las categorías de la escala ordinal. Los únicos pacientes que podrían beneficiarse son aquellos que se encuentran hospitalizados con requerimiento de oxígeno suplementario, aunque no puede descartarse que esta conclusión no esté influenciada por el mayor número de pacientes que engloba esta categoría (39,75\% del total de pacientes enrolados). Dado el intervalo de confianza, se puede observar que el beneficio del remdesivir podría oscilar entre diez y un día menos de internación.

Otro de los aspectos a destacar, es que el desenlace primario fue modificado mientras el estudio se encontraba en curso, mediante enmiendas al protocolo. Inicialmente, éste consistía en la diferencia en el estado clínico al día 15. Al mes de iniciado el trabajo, cuando ya se habían enrolado $72(6,8 \%)$ pacientes, y sobre la base de la evidencia que sugería que la infección por COVID-19 podría tener un curso clínico más prolongado, se propuso cambiarlo por tiempo medio de recuperación durante los 28 días de seguimiento. Dados los múltiples interrogantes que nos plantea el SARS-CoV-2, este cambio podría ser comprensible, y si bien los estadísticos estaban ciegos al momento de proponer el cambio, no deja de ser cuestionable la modificación de los desenlaces en el transcurso de un ensayo clínico.

Por otro lado, identificamos la presencia de sesgo de notificación al detectar que no todos los resultados previstos fueron publicados. Uno de los desenlaces propuestos era la mortalidad al día 14 y 28 , sin embargo, sólo fueron reportadas las muertes al día 14. Este hecho nos parece relevante ya que, precisamente al entender el curso clínico más prolongado de la enfermedad y considerando que al momento en que se decide finalizar el estudio la tercera parte de los pacientes aún no había completado el seguimiento, la mortalidad al día 28 podría ser un desenlace de vital importancia. Además, si bien se estimó que el grupo tratado con remdesivir tuvo $30 \%$ menos de probabilidad de muerte que el grupo tratado con placebo, la amplitud del intervalo de confianza muestra que estos resultados no fueron estadísticamente significativos.

Por último, si bien oficialmente no se reportaron conflictos de interés, se ha revelado que Gilead (el laboratorio creador del remdesivir) suministró el medicamento para el ensayo, uno de los investigadores del ensayo era un empleado de Gilead y otros seis autores declararon vínculos financieros con esta empresa. Además los empleados de Gilead participaron activamente en discusiones junto con el equipo del protocolo. Todo esto sugiere que no se puede considerar que este trabajo sea independiente de los intereses del fabricante ${ }^{5}$.

Mientras tanto, y a pesar de los resultados interinos del estudio Solidarity difundidos el 15 de octubre de este año, que señalan que los cuatro tratamientos evaluados (remdesivir, hydroxicloroquina, lopinavir/ritonavir e interferón) tuvieron poco o ningún efecto sobre la mortalidad global, la iniciación de la ventilación y la duración de la estadía hospitalaria en pacientes hospitalizados ${ }^{6,7}$, el 22 de octubre la FDA otorgó la aprobación del uso de remdesivir en adultos y niños de 12 años o mayores y al menos 40 kilogramos de peso para el tratamiento del COVID-19 que requiera hospitalización ${ }^{8}$.

\section{Conclusiones de las comentadoras}

Comprendemos que en esta situación de pandemia es necesario tomar decisiones con celeridad sobre la base de la mejor evidencia disponible, por lo que los investigadores se encuentran en una especie de carrera por encontrar (y publicar) los mejores tratamientos para el COVID-19. Tal es así, que se ha estimado que The Lancet está recibiendo tres veces la cantidad habitual de artículos para publicar, y el New England Journal of Medicine, ha llegado a recibir hasta 200 presentaciones en un mismo día, poniendo el proceso de revisión de pares al borde de la saturación. Esto ha hecho que evidencia dudosa y, en muchos casos, contradictoria, se utilice para la toma de decisiones de políticas sanitarias implicando una considerable inversión en salud, y creando expectativa en quienes esperan beneficiarse con dichos tratamientos.

En este contexto, nos parece relevante preguntarnos hasta qué punto vale la pena sacrificar evidencia de alta calidad, a expensas de tener nueva información rápida. A pesar de la urgencia por encontrar un tratamiento que logre controlar la pandemia mundial de COVID-19, opinamos que esto no nos habilita a conformarnos con resultados parciales, a que los Estados inviertan en recursos para proveer tratamientos de dudosa eficacia y seguridad, y menos aún, a que perdamos de vista el compromiso ético para con los pacientes de la investigación en salud y nos dejemos llevar por las influencias de la 
industria farmacológica.

Si se pudo realizar un estudio como el Recovery en el Reino Unido, con resultados de buena calidad sobre una droga de bajo costo y bien conocida como la dexametasona, ¿por qué tendríamos que basar la toma de decisiones en base a ensayos clínicos en curso sobre una nueva droga para un nuevo uso?

Agostina Risso, Antonella Stellardo [ Servicio de Medicina Familiar y Comunitaria, Hospital Italiano de Buenos Aires. agostina.risso@hospitalitaliano. org.ar, antonella.stellardo@hospitalitaliano.org.ar ]

Risso A, Stellardo A. Remdesivir como tratamiento para COVID-19. Evid Actual Pract Ambul. 2020;23(4):e002100. Comentado de: Beigel JH, et al. Remdesivir for the Treatment of Covid-19 - Final Report. N Engl J Med. 2020 Oct 8;NEJMoa2007764. doi: 10.1056/NEJMoa2007764. PMID: 32445440

\section{Referencias}

1. Beigel JH, Tomashek KM, Dodd LE, et al. Remdesivir for the Treatment of Covid-19 - Final Report. N Engl J Med. 2020;p. NEJMoa2007764. Available from: 10.1056/NEJMoa2007764.

2. McCreary EK, Angus DC. Efficacy of Remdesivir in COVID-19. JAMA. 2020;324(11):1041-1042. Available from: 10.1001/jama.2020.16337.

3. Garegnani LI, Arancibia M, Madrid E, et al. Clinical trials with sequential analysis that were early-stopped: How to interpret them? Medwave. 2020;20(5):e7930. Available from: 10.5867/medwave.2020.05.7930

4. Guyatt G, Rennie D, Meade MO, et al. Users' Guides to the Medical Literature: Essentials of Evidence-Based Clinical Practice. 2nd ed. McGraw Hill Professional; 2008.

5. Moynihan R, Macdonald H, Bero L, et al. Commercial influence and covid-19. BMJ. 2020;369:m2456. Available from: 10.1136/bmj.m2456.

6. "Solidarity" clinical trial for COVID-19 treatments. UPDATE: Solidarity Trial reports interim results.; 2020. Available from: https://www.who.int/ emergencies/diseases/novel-coronavirus-2019/global-research-on-novel-coronavirus-2019-ncov/solidarity-clinical-trial-for-covid-19-treatments.

7. WHO Solidarity trial consortium. Repurposed antiviral drugs for COVID-19 -interim WHO SOLIDARITY trial results;. Available from: https://doi.org/ $10.1101 / 2020.10 .15 .20209817$.

8. La FDA aprueba el primer tratamiento para el COVID-19; 2020. Available from: https://www.fda.gov/news-events/press-announcements/lafda-aprueba-el-primer-tratamiento-para-el-covid-19\#: :text=(FDA\%2C\%20por\%20sus\%20siglas\%20en,COVID\%2D19\%20que\%20requiera\% 20 hospitalizaci\%C3\%B3n. 